REVISTA X, Curitiba, volume 13,n.1,p.192-198, 2018.

\title{
DE UMA ILHA DISTANTE AO CORAÇÃO DA AMAZÔNIA: CAMINHOS DE UM CUBANO ATRAVESSẢDOS PELO PORTUGUÊS
}

\section{From a Far Away Island to the Heart of Amazon: Crossed Pathways of a Cuban with the Portuguese Language}

Herling Hernández STERLING, Ministerio de la Salud Pública - Cuba ${ }^{1}$

Eis que o povo é um, e todos têm uma mesma língua; e isto é o que começam a fazer; e agora, não haverá restrição para tudo o que eles intentarem fazer. Eia, desçamos e confundamos ali a sua língua, para que não entenda um a língua do outro (Gn 11, 6:7)

Desde a infância, sempre tive curiosidade e sempre quis conhecer o mundo. Meu avô me contava histórias de terras distantes na África e suas planícies com girafas, leões e elefantes, da Amazônia e seu poderoso rio com anacondas e piranhas e suas selvas virgens, todas cheias de pássaros exóticos e comunidades indígenas que nunca tiveram contato com outros povos. Histórias fantásticas que enriqueceram minha infância e fizeram com que minha imaginação voasse longe da minha pequena ilha. Foi assim, graças a todas as histórias de meu avô, que fiz viagens maravilhosas.

Já na escola, conheci realmente tudo, ou quase tudo, referente ao Brasil. Cultura, tradições, extensão territorial, história, línguas, tudo que um estudante de doze anos pode receber na aula de geografia. Soube que o Brasil, apesar de pertencer à América do Sul e à América Latina, não falava espanhol, por ter sido colonizado por Portugal. Esse fato sempre intrigou minha cabeça de estudante. Como era o português? Com certeza, uma língua esquisita e enrolada, difícil de falar.

Minhas dúvidas foram todas esclarecidas quando, aos quatorze anos, tive meu primeiro contato com a língua portuguesa, graças à magia do cinema. Foi um filme brasileiro chamado Dona Flor e seus dois maridos, algo que, para a época, era um

1 Médico do Ministerio de la Salud Pública - Cuba. Atualmente, é médico no Brasil, por meio do Programa Mais Médicos para o Brasil, trabalhando em Brasiléia (AC). Email: herlinghsterling@gmail.com 
REVISTA X, Curitiba, volum e 13,n.1,p.192-198, 2018.

Dossiê Especial: Português como Língua Adicional em contextos de minorias:

(co)construindo sentidos a partir das margens

BIZON \& DINIZ (Orgs.)

pouquinho escandaloso e, por isso, proibido para menores de dezoito anos. Meu irmão e eu tivemos de entrar escondidos, sem que ninguém notasse. Assistimos a todo o filme escondidos, com nossos corações batendo rápido e receando sermos surpreendidos. Para nossa pouca idade, foi um acontecimento digno de aventura. Quase como um Errol Flint ou um Indiana Jones. Foi assim que nos sentimos. Ao longo do filme, percebi que o português era bastante semelhante ao nosso idioma, embora não pudéssemos entender o que os personagens estavam falando e tivéssemos que ler as legendas. Reconhecíamos algumas palavras que nos recordavam o espanhol, mas não sabíamos se elas significavam o mesmo. Ficamos fãs daquela nova língua - meu irmão passou a se ver como um verdadeiro "especialista", mesmo que ele só soubesse palavras como "obrigado", "bom dia" e algumas palavras pouco educadas. Eu também me sentia poliglota e, junto com meu irmão, espantava outras crianças da nossa idade contandolhes nossa aventura de entrarmos clandestinamente no cinema e dele sairmos com "vasto" conhecimento de uma língua estrangeira.

Meu segundo contato com o português foi quando eu estava um pouco mais crescido, já na Universidade de Medicina. Esta oportunidade não veio sob a forma de filme ou música. Veio em forma de uma mulher, com toda a força do rio amazônico em seus olhos, com toda a exuberância da selva em seu corpo e com toda a música e o ritmo em suas pernas, em seus quadris e em sua cintura. Ela era o samba feito mulher. Claro que me apaixonei por ela. E, embora ela falasse espanhol quase que perfeitamente, eu me preparava para tentar aprender seu idioma. Pareceu-me uma maneira de chamar sua atenção e me fazer ver por essa deusa carioca. Tive que contar com ajuda dos meus colegas brasileiros da graduação. Eles me ensinavam apenas palavras grosseiras, apesar dos meus contínuos protestos de que não era delas que precisava. Eu não poderia lhes dizer que queria aprender a língua deles para conquistar uma mulher, embora me parecesse romântico, pois eles ririam de mim e de minhas torpes tentativas de aprender a língua. No entanto, eu estava disposto a suportar as piadas apenas para ter sucesso em aprender, mesmo que apenas um pouco, aquela língua que parecia um abismo que me separava de uma mulher que eu já idolatrava, embora com ela quase não tivesse falado. O português era uma ferramenta que eu 
REVISTA X, Curitiba, volume 13,n.1,p.192-198, 2018.

Dossiê Especial: Português como Língua Adicional em contextos de minorias:

(co)construindo sentidos a partir das margens

BIZON \& DINIZ (Orgs.)

precisava dominar e estava disposto a sacrificar até a minha maltratada dignidade para obtê-la.

Depois de vários meses de aprendizado árduo e graças aos meus professores improvisados, consegui adquirir um vocabulário em português de um menino de três anos, mas isso parecia ser suficiente para conseguir um olhar diferente dela, ou mesmo um sorriso, por simpatia, admiração ou pura compaixão. Qualquer coisa que ela me dava era uma vitória. Lembro-me que as primeiras palavras que, depois de um "bom dia", disseram meus dentes foram: "Quero aprender a dançar samba. Quer ser minha professora de dança?" Eu realmente ganhei mais do que precisava: em vez de um sorriso de admiração ou de cumplicidade, ouvi uma gargalhada dos meus colegas de classe. No entanto, seus olhos começaram a me olhar de outro jeito: sabia que, estranhamente, os meses de tentativas fracassadas e risos de meus companheiros não haviam sido em vão.

Ela foi a causa e o princípio de tudo. Aprendi com ela sobre a música brasileira, a comida, as tradições, os cantores, a poesia, seus escritores, a magia de suas cidades, o calor da sua população, a brancura de suas praias. Nasceu em mim uma fascinação pelo Brasil ou por qualquer coisa que tivesse a ver com ele, algo quase obsessivo e sobrehumano.

A vida é estranha, com todas as suas voltas. Às vezes não sabemos o que o destino nos preparou, se o destino estiver lá. Se alguém me dissesse, não acreditaria nisso. Quinze anos depois de conhecer esse amor da juventude, tive a oportunidade de vir ao Brasil para trabalhar em um projeto ambicioso e inovador, certamente único em seu alcance, que tem feito a diferença na vida de muitas pessoas: o programa Mais médicos para o Brasil, que reúne médicos brasileiros e estrangeiros dispostos a trabalhar em áreas remotas, rurais, distritos indígenas, periferias. Regiões que, por vezes, são de acesso muito difícil, e que nunca, ou quase nunca, viram um médico. Embora ofereça atenção a qualquer pessoa que more no Brasil, o programa tem como foco, em particular, as pessoas menos favorecidas ou mais empobrecidas do Brasil, que, devido a questões geográficas, históricas e sociais, têm pouco ou nenhum acesso a um serviço de saúde. 
REVISTA X, Curitiba, volum e 13,n.1,p.192-198, 2018.

Dossiê Especial: Português como Língua Adicional em contextos de minorias:

(co)construindo sentidos a partir das margens

BIZON \& DINIZ (Orgs.)

Sou um dos médicos selecionados para o programa. Sinto-me privilegiado com a possibilidade de participar e prestar atendimento médico a uma parte da população carente do Brasil. Antes de embarcar nessa missão para contribuir com o fortalecimento do Sistema Único de Saúde brasileiro, precisei encarar, com outros companheiros, cursos de português em Cuba. Pelo fato de que trabalharíamos, principalmente, com pessoas mais humildes, com pouco acesso à escolarização de qualidade, a barreira linguística parecia ainda maior. Imagino que tudo isso significou também um grande desafio para nossos professores.

Foi aqui no Brasil que percebi que uma coisa é ouvir um professor que dá aula de português, com um português claro, limpo, devagar, acadêmico; outra coisa completamente diferente é escutar um português popular falado com total naturalidade e facilidade. A realidade me mostrou o quão difícil é estar em um país estrangeiro, com um idioma completamente diferente do seu. Para minha sorte, no hotel onde, em Brasília, fiquei hospedado por duas semanas ao chegar ao Brasil, conheci um balconista muito amigável, que me serviu como interlocutor e ao mesmo tempo de guia turístico. Foi a primeira pessoa com quem bati papo aqui no Brasil. Ele também falava inglês e espanhol com eficiência e fluência invejáveis, mas sempre tentei me comunicar em português ou pelo menos no que eu assumi que deveria ser um português razoavelmente decente. Assim, passei os primeiros dias neste país. Em minha mente, infantilmente, comparei-me com um alienígena que visitava a terra pela primeira vez. Talvez pudesse ter pensado em melhores exemplos, mais verossímeis, mas, para enfrentar situações difíceis, sempre criei situações engraçadas para que minha mente se adaptasse melhor às mudanças e reduzisse o estresse.

Coube a mim um posto de trabalho na região da Amazônia, mais especificamente, no Acre. Uma região que, segundo meu colega balconista dizia humoristicamente, não existia para o povo brasileiro, devido a tantas piadas contadas às custas de pessoas que lá moram. Tenho que ser honesto e dizer que minha primeira reação foi preocupante, porque desconhecia totalmente o que eu enfrentaria em uma área tão distante do Brasil, na fronteira com a Bolívia. Pelo que me contaram, esse município se chamava, inicialmente, Brasília, mas precisou mudar de nome quando foi 
REVISTA X, Curitiba, volume 13,n.1,p.192-198, 2018.

Dossiê Especial: Português como Língua Adicional em contextos de minorias:

(co)construindo sentidos a partir das margens

BIZON \& DINIZ (Orgs.)

fundada a atual capital do Brasil, passando a se chamar, a partir de então, Brasiléia: uma mistura do nome anterior com uma segunda palavra que se refere à folhagem das árvores. Confesso que estava decepcionado com a ideia de trabalhar tão longe das grandes cidades e, equivocadamente, acreditava que os moradores de Brasiléia saberiam falar espanhol, devido à proximidade com a Bolívia. Foi uma grande surpresa saber que eles não falavam espanhol, com exceção de algumas pessoas que tinham origem boliviana ou que haviam trabalhado ou estudado no país vizinho. Também foi uma surpresa muito agradável encontrar a equipe boliviana trabalhando no programa Mais Médicos.

O maior desafio era enfrentar uma consulta unicamente em português, ou pelo menos era o que eu pensava. Logicamente, adornada com algum componente linguístico hispânico e algum gesto - linguagem corporal que, talvez universalmente, usem todas as pessoas com pouco ou nenhum conhecimento de outro idioma. No meu caso, esses recursos serviam também para preencher algumas palavras vazias de sentido para alguns de meus pacientes, pouco familiarizados com termos médicos. Outro grande problema dizia respeito aos regionalismos, isto é, aos distintos modos como as pessoas chamam as mesmas coisas conforme a região do Brasil. Palavras como pau da venta (nariz), sovaco (axila), cangote (pescoço), bolacha do joelho (rótula), mocotó (tornozelos) e zói (olhos) são comuns no Acre.

Posso dizer, sem dúvida, que o maior desafio que enfrentei até aqui, nesta terra da Amazônia, foi durante um itinerário para uma área rural chamada Torjal, a cerca de $140 \mathrm{~km}$ de Brasiléia. Atravessamos a selva por um percurso estreito, cheio de buracos e valas, às vezes muito próximo do avanço da floresta. Parecia que as árvores tentavam reivindicar o que homem tirou com a borda do facão e o equipamento pesado. A fim de chegar cedo a Torjal e aproveitar melhor o tempo, saímos às três da manhã. Uma equipe de dezesseis pessoas: três motoristas, três membros da equipe de gerenciamento da secretaria de saúde, sete enfermeiros e três médicos. A "expedição", como eu batizei a viagem, foi realizada graças aos esforços feitos pela secretaria de Saúde e pela prefeitura de Brasiléia. A rota para chegar ao local foi longa e sinuosa: qualquer montanha-russa invejaria aquela estrada. Todos, ou pelo menos, os menos acostumados, 
REVISTA X, Curitiba, volum e 13,n.1,p.192-198, 2018.

Dossiê Especial: Português como Língua Adicional em contextos de minorias:

(co)construindo sentidos a partir das margens

BIZON \& DINIZ (Orgs.)

entre os quais me incluo, chegamos tontos. Precisamos de um tempinho para nos recuperar. Nunca havia visto nada assim antes. Uma natureza semivirgem, chocante, que me atingia com todo o verde do mundo, como se o mundo não fosse de outra cor, fazendo lembrar que o verde é a vida em toda sua plenitude. Essa paisagem ficará gravada para sempre em minha mente. Durante toda a viagem, pensava em meu avô e em todas as suas histórias sobre a África que inflamaram em mim a chama da curiosidade e da aventura. Fiquei feliz, fiquei muito feliz. Com essa felicidade limpa, pura, com essa pureza que nenhum objeto material pode conferir, porque surge da raiz do sentimento mais essencial, porque surge da contemplação do maravilhoso, do irrepetível.

Quando finalmente chegamos, esperava-nos uma população realmente ansiosa. Crianças descalças, sorridentes e curiosas. Mães e pais carregando seus pequeninos, sabe-se lá de que distância. Cerca de cem pessoas foram consultadas nesse dia, e tantas outras foram vacinadas. O conhecimento do idioma novamente nos colocou à prova, desta vez porque essas pessoas falavam de um jeito rápido, atropelado, com palavras cujo significado não entendíamos, porque elas pareciam totalmente novas. Frequentemente, precisávamos da ajuda de uma enfermeira para servir como tradutora, para entendê-los e nos fazer entender. Enquanto estávamos fazendo consultas, aumentávamos nosso vocabulário, tanto com palavras que reconhecíamos mais facilmente - como zoreia, zumbigo, zouvido -, quanto com outras totalmente novas, como pereba, que significa ferida, pé da barriga, que se refere ao abdômen inferior, curuba, que significa escabiose. Falavam muito rápido, embaralhando uma palavra com a seguinte. Um sotaque caipira, diferente de tudo que havia escutado até então. Até para alguns brasileiros da equipe era difícil entender.

Mas o que todos percebemos, sem dificuldade, foi a gratidão pintada em seus rostos, por trás de uma aparência desalinhada, às vezes não tão arrumada, ou mesmo rústica. As pessoas pareciam não conseguir expressar o quão bem elas nos queriam ou o que sentiam, mas seus olhos refletiam uma espécie de admiração e agradecimento, tudo junto, misturado. Os seus sorrisos nos disseram a importância de nossa missão. Aquele era um lugar aonde nenhuma enfermeira ou médico haviam ido até então. 
REVISTA X, Curitiba, volume 13,n.1, p. 192-198, 2018.

Dossiê Especial: Português como Língua Adicional em contextos de minorias:

(co)construindo sentidos a partir das margens

BIZON \& DINIZ (Orgs.)

Sou médico há onze anos, então posso dizer que já vi o suficiente no meu dia a dia, mas é por imagens e situações como aquelas que eu vivi naquele dia que sou grato à oportunidade de ter me tornado médico. São esses momentos que nos lembram a importância do nosso trabalho e por que escolhemos salvar vidas em primeiro lugar. Esta magnífica viagem ao interior de Torjal não só serviu para admirar a grandeza da selva amazônica, não só para reviver momentos com meu avô e suas histórias, não só para aprender palavras novas e até engraçadas de gíria popular. Também me ajudou a aprender a valorizar a importância de um conhecimento profundo da linguagem melódica desta incrível terra. Mas, mais importante ainda, me deixou novamente apaixonado por minha profissão. É algo pelo qual sempre agradecerei.

Agradeço pelo fato de hoje poder, com meu português cubano - aquele que comecei a saborear em minha querida ilha, sem nunca imaginar que um dia seria eu o protagonista das histórias do meu avô -, percorrer um pouco do Acre. Ao contrário do que dizia meu amigo balconista de Brasília, o Acre não só existe. Ele está vivo. Porque, em seu povo, circula o sangue como se fosse a água do rio Acre, porque esse povo carrega a castanha e o cupuaçu em sua carne, mas também carrega muitos sonhos em seus olhares. O Acre bate no coração de seu povo, no coração da Amazônia. E sou feliz por hoje dele também fazer parte. 